\title{
Determination of Volatiles in Pharmaceutical Certified Reference Materials
}

\author{
Raquel Nogueira, ${ }^{*, a}$ Suzane M. Queiroz, ${ }^{a}$ Gisele E. B. Silva, ${ }^{a}$ Werickson F. C. Rocha, ${ }^{a}$ \\ Gabriel F. Sarmanho, ${ }^{a}$ Renato R. R. Almeida ${ }^{a}$ and Gabriela F. Moreira ${ }^{b}$ \\ ${ }^{a}$ Chemical Metrology Division (Dquim) and ${ }^{b}$ Materials Metrology Division (Dimat), \\ National Institute of Metrology, Quality and Technology (INMETRO), 25250-020 Xerém-RJ, Brazil
}

\begin{abstract}
Este trabalho compara os resultados obtidos na determinação de voláteis (água e solventes residuais) em novos materiais de referência certificados (MRC) ou candidatos a MRC dos ingredientes ativos farmacêuticos (API) captopril, metronidazol, diclofenaco sódico, diclofenaco potássico e furosemida, através do uso de diferentes técnicas: perda por dessecação (LOD), titulação coulométrica tipo Karl Fisher (KF), cromatografia gasosa (injeção por headspace estático) com detector por ionização em chama (sHS-GC-FID) e com espectrômetro de massas (sHS-GC-MS), análise termogravimétrica (TGA) e espectroscopia no infravermelho próximo (NIR) com análise estatística multivariada dos resultados. As três primeiras técnicas levaram a resultados complementares na determinação de voláteis, enquanto as outras duas mostraram pouca sensibilidade para a determinação de voláteis na faixa de concentração avaliada. A perda por dessecação foi considerada a técnica mais apropriada para determinação da fração mássica de voláteis a ser utilizada no cálculo do teor de API por balanço de massa.
\end{abstract}

This work compares the results obtained for the determination of volatiles (water and residual solvents) in new certified reference materials (CRM) or candidate CRMs of the active pharmaceutical ingredients (API) captopril, metronidazole, sodium diclofenac, potassium diclofenac and furosemide, by means of different techniques: loss on drying (LOD), Karl Fischer (KF) coulometric titration, static headspace gas chromatography with flame ionization detection (sHS-GC-FID) and with mass spectrometry (sHS-GC-MS), thermogravimetric analysis (TGA) and near infrared spectroscopy (NIR) with multivariate chemometric analysis of results. The first three methods led to complementary results. The two other techniques were not sufficiently sensitive to determine volatiles in the concentration range evaluated. The loss on drying method was considered the most appropriate to determine the mass fraction of the volatiles to be used in the mass balance calculation of the API mass fraction in the pharmaceutical CRMs.

Keywords: volatiles, water, residual solvents, active pharmaceutical ingredient (API), certified reference materials (CRM), analytical quality control

\section{Introduction}

Several are the reasons for determining the mass fractions of water and residual solvents in pharmaceuticals, including their influence on the physicochemical ${ }^{1-7}$ and microbiological stability of raw materials and finished products, their potential toxicity ${ }^{1-3,8}$ and also economic aspects ${ }^{9}$ since their presence results in analyte mass fractions smaller than $100 \%$. Residual solvents may be introduced in active pharmaceutical ingredients (API) during their synthesis, especially if the final purification step is carried

*e-mail: rnogueira@inmetro.gov.br out by crystallization in different solvents, as well as during drug products formulation and manufacturing. 1,7,8

In the particular case of certified reference materials (CRM) of APIs, the determination of volatiles is essential both to demonstrate the compliance with Pharmacopeial acceptance criteria and to allow the mass balance calculation $\left(100 \%-\sum \text { impurities }\right)^{10-12}$ of the API mass fraction. CRMs are produced according to the ISO Guides 34:2009 13 and 35:2006 ${ }^{14}$ and find application in equipment calibration, method validation and quality control. Unlike typical reference materials (RM), CRMs ensure metrological traceability of measurement results to the International System (SI) of Units, which means 
an unbroken chain of calibrations, each contributing to the measurement uncertainty, ${ }^{15,16}$ and is a requirement for accredited laboratories under ISO/IEC 17025:2005. ${ }^{17}$ Even if in several fields the use of CRMs is a well-established practice, in the pharmaceutical area only a few are available, including four CRMs from the United States Pharmacopeial Convention (USP), ${ }^{18} 17 \beta$-estradiol CRM from the National Metrology Institute of Japan (NMIJ), ${ }^{19}$ paclitaxel CRM from the National Metrology Institute of China (NIM), ${ }^{20}$ as well as the CRMs of captopril, ${ }^{21,22}$ metronidazole ${ }^{23}$ and sodium diclofenac from the National Institute of Metrology, Quality and Technology (INMETRO, Brazil).

Volatiles in pharmaceuticals are mainly represented by water and residual solvents. The free or surface water ${ }^{4,5}$ is the main responsible for sample degradation, ${ }^{24}$ while the hydration or crystal water ${ }^{4,24}$ that is held inside the crystal lattice is less available to promote hydrolysis or other degradation reactions. ${ }^{4}$ The adsorption of water from the air can be monitored by moisture sorption isotherms. ${ }^{25}$ The residual solvent classes and limits according to the ICH Q3C(R5) Guideline ${ }^{26}$ and to the United States Pharmacopeia 2011 (USP 34) ${ }^{27}$ are given in Table 1.

In the following paragraphs, different analytical techniques used to determine volatiles in pharmaceuticals are discussed: Karl Fischer, loss on drying, gas chromatography, thermogravimetry, spectroscopy and nuclear magnetic resonance.

The Karl Fischer (KF) reaction is based on the quantitative reaction of water with iodine $\left(\mathrm{I}_{2}\right)$ in presence of an alcohol, a base, and sulfur dioxide $\left(\mathrm{SO}_{2}\right)$, with potentiometric determination of the endpoint. The most known mechanism was proposed by Scholz in 1984: ${ }^{28}$

Table 1. Residual solvent classes and limits in pharmaceuticals ${ }^{26,27}$

\begin{tabular}{|c|c|c|c|c|c|c|c|c|}
\hline Class & Solvent & Limit / ppm & Class & Solvent & Limit / ppm & Class & Solvent & Limit / ppm \\
\hline \multirow[t]{28}{*}{ I } & benzene & 2 & II & acetonitrile & 410 & III & acetic acid & 5000 \\
\hline & carbon tetrachloride & 4 & & chlorobenzene & 360 & & acetone & \\
\hline & 1,2-dichloroethane & 5 & & chloroform & 60 & & anisole & \\
\hline & 1,1-dichloroethene & 8 & & cumene & 70 & & 1-butanol & \\
\hline & 1,1,1-trichloroethane & 1500 & & cyclohexane & 3880 & & 2-butanol & \\
\hline & & & & 1,2-dichloroethene & 1870 & & butyl acetate & \\
\hline & & & & dichloromethane & 600 & & tert-butyl methylether & \\
\hline & & & & 1,2-dimethoxyethane & 100 & & dimethylsulfoxide & \\
\hline & & & & $N, N$-dimethylacetamide & 1090 & & ethanol & \\
\hline & & & & $N, N$-dimethylformamide & 880 & & ethyl acetate & \\
\hline & & & & 1,4-dioxane & 380 & & ethyl ether & \\
\hline & & & & 2-ethoxyethanol & 160 & & ethyl formate & \\
\hline & & & & ethyleneglycol & 620 & & formic acid & \\
\hline & & & & formamide & 220 & & heptane & \\
\hline & & & & hexane & 290 & & isobutyl acetate & \\
\hline & & & & methanol & 3000 & & isopropyl acetate & \\
\hline & & & & 2-methoxyethanol & 50 & & 3-methyl-1-butanol & \\
\hline & & & & methylbutyl ketone & 50 & & methylethyl ketone & \\
\hline & & & & methylcyclohexane & 1180 & & methylisobutyl ketone & \\
\hline & & & & $\mathrm{N}$-methylpyrrolidone & 530 & & 2-methyl-1-propanol & \\
\hline & & & & nitromethane & 50 & & pentane & \\
\hline & & & & pyridine & 200 & & 1-pentanol & \\
\hline & & & & sulfolane & 160 & & 1-propanol & \\
\hline & & & & tetrahydrofuran & 720 & & 2-propanol & \\
\hline & & & & tetralin & 100 & & propyl acetate & \\
\hline & & & & toluene & 890 & & & \\
\hline & & & & trichloroethene & 80 & & & \\
\hline & & & & xylene & 2170 & & & \\
\hline
\end{tabular}


$\mathrm{ROH}+\mathrm{SO}_{2}+\mathrm{R}^{\prime} \mathrm{NH} \rightarrow\left[\mathrm{R}^{\prime} \mathrm{NH}\right] \mathrm{SO}_{3} \mathrm{R}$

$\mathrm{H}_{2} \mathrm{O}+\mathrm{I}_{2}+\left[\mathrm{R}^{\prime} \mathrm{NH}\right] \mathrm{SO}_{3} \mathrm{R}+2 \mathrm{R}^{\prime} \mathrm{N} \rightarrow\left[\mathrm{R}^{\prime} \mathrm{NH}\right] \mathrm{SO}_{4} \mathrm{R}+$

2[R'NH]I

where R'N represents a base, e.g., pyridine or the less toxic imidazole,, 929 while $\mathrm{ROH}$ represents an alcohol, usually methanol, ${ }^{9,24}$ but also ethanol, ethylene glycol and 2-methoxyethanol. ${ }^{11}$

The Karl Fischer method is used to determine the total water content, i.e., surface and crystallization water., ${ }^{7,911}$ For larger water amounts $(1-100 \%),{ }^{24,30}$ the volumetric titration (titrant added directly to the titration chamber) is the most indicated, while the coulometric titration (iodine titrant formed in the generator electrode) is appropriate for water amounts in the order of 10-20 $\mu \mathrm{g},{ }^{11} 50-100 \mathrm{ppm},{ }^{24}$ or few $\mu \mathrm{g} \mathrm{g}^{-1} \cdot{ }^{30}$ Both methods can be carried out either by direct introduction of samples in the titration chamber or by using an oven that heats the sample to vaporize the water, which is then transferred to the titration cell by a stream of an inert gas.

The KF method is highly selective to water ${ }^{24,30}$ and very reproducible. ${ }^{6}$ The oven method can differentiate between bound surface and crystallization water by using a defined temperature gradient, ${ }^{29}$ but it cannot be applied for thermolabile compounds. ${ }^{24}$ Another drawback of the technique is the restriction to use the direct addition in case of analytes that are not soluble in or that react with the KF reagent, ${ }^{6,29}$ for instance thiols, ${ }^{11,31}$ aldehydes, cetones, amines, cupric salts and ferric salts. ${ }^{11}$ Furthermore, it does not provide information about residual solvents.

The loss on drying (LOD) technique is largely used in pharmaceutical laboratories to determine the total amount of volatiles, i.e., water and residual solvents ${ }^{9,29,32}$ vaporized under the experimental conditions. The test is quite simple, ${ }^{3,29}$ and depends only on a properly calibrated analytical balance and an oven usually programmed at $105^{\circ} \mathrm{C}$ (or a vacuum oven in case of thermolabile APIs). In metrological terms, LOD has the advantage of being a gravimetric technique and consequently a primary method of measurement. ${ }^{15}$ Balances with infrared drying are also used for the mass loss method, ${ }^{24}$ but are not sufficiently accurate and are appropriate only for comparative measurements (e.g., drying of granulates prior to tablet compression). LOD is considered a non-specific technique $^{3}$ and may form interfering volatile components due to sample thermal degradation. ${ }^{11,29}$ Additionally, the technique may not release all the entrained solvent ${ }^{1}$ or tightly bound crystallization water. ${ }^{29,32}$ Other disadvantages are the large amount of sample required ${ }^{1,3,29}$ and the long analysis time. . $^{92,29}$

Gas chromatography (GC) is the most used technique for residual solvent quantification. ${ }^{33}$ The flame ionization detector (FID) is the commonly used detector for quantitative purposes due to its almost "universal" response (no water response is given by FID), ${ }^{34}$ the mass spectrometer (MS) detector is usually applied for identification, while the electron capture detector (ECD) is dedicated for halogenated compounds.

The static headspace gas chromatography (sHS-GC) is the Pharmacopeial method to determine residual solvents. The dissolved sample ${ }^{27,35}$ is heated in a closed vial, an equilibrium is established between upper gas phase and lower liquid phase, ${ }^{2}$ and then a fixed gas phase volume (i.e., only volatile components) is injected into the GC column. ${ }^{8}$ In equilibrium, the residual solvent concentration in the gas phase $\left(\mathrm{C}_{\mathrm{g}}\right)$ is expressed as: ${ }^{2,34}$

$\mathrm{C}_{\mathrm{g}}=\mathrm{C}_{0} /(\mathrm{K}+\beta)$

where $\mathrm{C}_{0}$ is the original residual solvent concentration in the condensed phase (sample solution or solid sample), $\mathrm{K}$ is the partition coefficient between condensed and gas phases, and $\beta$ is the phase volume ratio (gas phase/ condensed phase).

The following parameters have to be carefully considered in sHS-GC analysis:

(i) diluent type: water is the best polar diluent for sHS-GC-FID since it gives no FID response and most of the residual solvents have low $\mathrm{K}$ values in water, ${ }^{8}$ which is desirable according to equation 1 . For less polar or apolar samples, high boiling point solvents such as $N, N$-dimethylformamide (DMF), dimethylsulfoxide $(\mathrm{DMSO})^{2,34}$ and $N, N$-dimethylacetamide (DMA) ${ }^{36}$ may be used. Since organic diluents seriously reduce the method sensitivity, ${ }^{2}$ water is usually added to the organic phase to reduce $\mathrm{K}$ and increase $\mathrm{C}_{\mathrm{g}}{ }^{2,37}$ Another alternative is the addition of salt solutions, e.g., $1 \mathrm{~mol} \mathrm{~L}^{-1} \mathrm{NaCl}$, to promote a "salting-out" effect of residual solvents. ${ }^{34,37}$ Diluents shall be purged with nitrogen prior to use for $3,{ }^{37} 4^{2}$ or $24 \mathrm{~h} ;{ }^{34}$ (ii) volume of diluent in the headspace vial: larger solution volumes inside the vial (smaller $\beta$ values) can reduce $C_{g}$ (equation 1 ), ${ }^{2}$ which is not desired;

(iii) headspace temperature: an increase in the headspace temperature increases $\mathrm{C}_{\mathrm{g}}{ }^{34}$ However, in case of water, the temperature is usually set to $80{ }^{\circ} \mathrm{C}$, i.e., $20^{\circ} \mathrm{C}$ below the water boiling point to avoid overpressure in the headspace vial. ${ }^{2,37,38}$ For diluents like DMF (b.p. $153^{\circ} \mathrm{C}$ ), ${ }^{35} \mathrm{DMSO}$ (b.p. $\left.189^{\circ} \mathrm{C}\right)^{35}$ and DMA (b.p. $166^{\circ} \mathrm{C}$ ), ${ }^{38}$ the used temperature shall not degrade either the solvent (e.g., DMF starts to degrade at $\left.120^{\circ} \mathrm{C}\right)^{34}$ or the analyte; $;, 34$

(iv) type of column: methyl, phenyl or cyanopropyl polysiloxanes are the most commonly used stationary phases due to their resistance to water vapor. ${ }^{8}$ The USP $34^{27}$ 
recommends the use of a $6 \%$ cyanopropyl-94\% dimethyl polysiloxane capillary GC column.

Usually, the residual solvent mass transferred to the headspace vial is around $2 \mu \mathrm{g} .{ }^{2}$ External and internal standard calibrations can be used..$^{1,39}$

Among the other GC methods, the dynamic headspace gas chromatography (dHS-GC) (purge-and-trap) has to be mentioned. In this technique, a gas flow is swept over the sample, the volatiles are trapped in a column (e.g., Tenax $^{\mathrm{R}}$ ) and then thermally desorbed for GC analysis., ${ }^{3,33}$ Although dHS-GC is more sensitive than sHS-GC due to the pre-concentration, ${ }^{1,3,38}$ it is less precise ${ }^{1}$ and does not reach $100 \%$ recovery. ${ }^{3}$ Additionally, the solid-phase microextraction gas chromatography (SPME-GC) is less often applied for pharmaceuticals and uses a silica fiber coated with a sorbent inside the sample vessel to adsorb volatiles (direct immersion or exposal to the headspace), for later desorption and GC analysis, ${ }^{1,33,40}$ with reported recoveries of at least $70 \% .{ }^{40}$ Finally, the direct GC injection is the least appropriate GC method since several APIs do not volatilize (except after derivatization) or are thermoinstable.

Thermogravimetric analysis (TGA) is another technique that can be applied to determine volatiles and is based on changes in sample weight when it is exposed to a temperature-time-program in a defined gas atmosphere..$^{29}$ The correct assignment of the type of volatile components, namely water or residual solvent, is easier to carry out when the equipment is connected to a mass spectrometer (TGA-MS). The technique requires only 2-5 mg sample ${ }^{1}$ and can recognize the types of water binding. ${ }^{29}$ The long analysis time may be a disadvantage.

The infrared spectroscopy (IR) has a high potential for identification (classification) and quantification, especially when combined to chemometric methods. ${ }^{5,41}$ It is non-destructive, requires minimum sample preparation, ${ }^{41}$ and can be used to determine water ${ }^{42}$ and residual solvents. ${ }^{3}$ The near infrared spectroscopy (NIR) $\left(800-2500 \mathrm{~nm} \text { or } 12821-4000 \mathrm{~cm}^{-1}\right)^{41}$ was reported to be the best method to differentiate between different water species. ${ }^{5}$ Strong absorption bands for water occur in the NIR spectral region, ${ }^{3,43}$ especially at $1420 / 1920 \mathrm{~nm}^{43}$ $\left(7040 / 5209 \mathrm{~cm}^{-1}\right)$ and $1450 / 1940 \mathrm{~nm}^{3,41}\left(6897 / 5150 \mathrm{~cm}^{-1}\right)$. According to Cao et al., ${ }^{5}$ NIR spectra at $1860-2020 \mathrm{~nm}$ ( $\mathrm{OH}$ stretching and $\mathrm{OH}$ bending) could be deconvoluted into individual spectra corresponding to hydrate and surface water of mannitol. The main IR drawback is its low sensitivity, usually above $100 \mathrm{ppm}$ or $1 \% .^{3,33}$ As water and volatiles are usually present in residual amounts in pharmaceuticals, the IR application becomes limited. Raman spectroscopy is not a good technique for water determination, but it was applied to monitor changes in the crystal lattice of an API, when the moisture content was reduced from 7 to $1 \%{ }^{42}$

The nuclear magnetic resonance (NMR) can be used for screening and identification of residual solvents. ${ }^{3,11}$ However, NMR is also reported to have high detection limits, ${ }^{3}$ and may not be sufficiently sensitive to determined water and residual solvents in pharmaceuticals. Additionally, the water present in deuterated solvents may be taken into account.

Other methods proposed in the literature to determine water or residual solvents are elemental analysis, ${ }^{11}$ phosphorus-pentoxide method ${ }^{29}$ and the azeotropic toluene distillation. $^{31}$

This work details the studies carried out to determine volatiles, i.e., water and residual solvents, in the first batches INMETRO of the new certified reference materials (CRMs) of captopril, metronidazole and sodium diclofenac, and of the candidate CRMs of potassium diclofenac and furosemide, using five different analytical techniques. The objective was to select the most appropriate method to determine volatiles in order to be used in the mass balance calculation of the API mass fraction in the pharmaceutical CRMs.

\section{Experimental}

\section{Karl Fischer coulometric titration and loss on drying}

The water mass fraction was determined using a Karl Fischer coulometer (831 model, Metrohm AG, Bleiche West, Switzerland) equipped with a generator electrode without a diaphragm, a current generator electrode $(400 \mathrm{~mA})$ and a platinum indicator electrode $(10 \mu \mathrm{A})$, connected to an oven sample processor (774 model, Metrohm), a stirrer (728 model, Metrohm) and a controller (774 SC model, Metrohm). The experimental conditions were: oven temperature of $80{ }^{\circ} \mathrm{C}$ (captopril) and $105^{\circ} \mathrm{C}$ (other APIs); end point voltage of $80 \mathrm{mV}$ for captopril and $50 \mathrm{mV}$ for the other APIs, extraction time of $300 \mathrm{~s}$; nitrogen-flow of $100 \mathrm{~mL} \mathrm{~min}^{-1}$. The results were processed with Tiamo ${ }^{\text {T.M. }} 1.2$ software (Metrohm, 2006).

The volatiles were determined by loss on drying, performed at $60{ }^{\circ} \mathrm{C}$ under vacuum for $3 \mathrm{~h}$ in case of captopril, at $105^{\circ} \mathrm{C}$ for $2 \mathrm{~h}$ in case of metronidazole and at $105^{\circ} \mathrm{C}$ for $3 \mathrm{~h}$ for the other APIs, according to the Brazilian Pharmacopeia IV. ${ }^{44}$

The sample amount used per replicate was $0.5 \mathrm{~g}$ (Karl Fischer) and $1.0 \mathrm{~g}$ (loss on drying). All samples were weighed in an analytical balance (Shimadzu, Tokyo, Japan), model AUW 220D, with resolution of $0.01 \mathrm{mg}$. 


\section{sHS-GC-FID and sHS-GC-MS}

For the headspace GC-FID analysis, a Focus gas chromatograph equipped with a Triplus headspace injector (Thermo Scientific, Waltham, MA, USA) was used. The results were processed using Chromquest 5.0 software. The experimental conditions, which were based on the USP $34^{27}$ were: WCOT fused silica CP-select 624 (Varian, Inc.; Palo Alto, USA), containing 6\% cyanopropyl phenyl and 94\% dimethylpolysiloxane, $30 \mathrm{~m} \times 0.32 \mathrm{~mm}$ i.d., $\mathrm{DF} 1.8$; helium gas-flow of $2.20 \mathrm{~mL} \mathrm{~min}^{-1}\left(35 \mathrm{~cm} \mathrm{~s}^{-1}\right.$ at $\left.40{ }^{\circ} \mathrm{C}\right)$; $\mathrm{GC}$ oven temperature gradient of $40{ }^{\circ} \mathrm{C}$ (holdtime $20 \mathrm{~min}$ ), $10{ }^{\circ} \mathrm{C} \mathrm{min}{ }^{-1}$ until $240{ }^{\circ} \mathrm{C}$ (hold time $20 \mathrm{~min}$ ); injector temperature of $140{ }^{\circ} \mathrm{C}$; FID temperature of $250{ }^{\circ} \mathrm{C}$; headspace thermostatting temperature of $80^{\circ} \mathrm{C}$; headspace thermostatting time of $60 \mathrm{~min}$; needle temperature of $85^{\circ} \mathrm{C}$; pressurization time of $30 \mathrm{~s}$; injection volume of $1 \mathrm{~mL}$; spit-ratio of 1:5. The headspace vials contained $0.5 \mathrm{~g}$ API and $6 \mathrm{~mL}$ of a mixture DMF-water $(5: 1, \mathrm{v} / \mathrm{v})$. For the construction of the calibration curves and the determination of the limit of quantification, sixteen individual solutions of ethyl acetate, isopropanol and acetone were prepared in the concentration ranges between 12 and $0.003 \mathrm{mg}$ of solvent in $6 \mathrm{~mL}$ of the mixture DMF-water (5:1, v/v).

The headspace GC-MS experiments were carried out in a CP3800 gas chromatograph with a $1200 \mathrm{~L}$ triple quadrupole, a 800 interface box and an ADC board from Varian, with a Combi PAL autosampler (CTC Analytics). Varian MS Workstation SP1 (System Control version 6.5) was used for system control. The experimental conditions were: WCOT fused silica CP-select 624 (Varian), as described above;

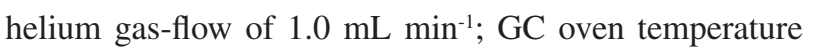
gradient of $40{ }^{\circ} \mathrm{C}$ (holdtime $20 \mathrm{~min}$ ), $10{ }^{\circ} \mathrm{C} \mathrm{min}{ }^{-1}$ until $240{ }^{\circ} \mathrm{C}$ (hold time $20 \mathrm{~min}$ ); injector temperature of $140^{\circ} \mathrm{C}$; transfer line temperature of $250^{\circ} \mathrm{C}$; ion source temperature of $230{ }^{\circ} \mathrm{C}$; ionization by electron impact at $70 \mathrm{eV}$; detector voltage of $1200 \mathrm{~V}$; headspace thermostatting temperature of $80^{\circ} \mathrm{C}$; headspace thermostatting time of $30 \mathrm{~min}$; needle temperature of $85^{\circ} \mathrm{C}$; injection volume of $1 \mathrm{~mL}$; spit-ratio $1: 10$. The MS detector was operated in scan mode from 30 to $500 \mathrm{amu}$ and was turned off during the dimethylformamide elution $\left(t_{R}\right.$ 25.8-26.5 min). The headspace vials contained $0.1 \mathrm{~g}$ API and $3 \mathrm{~mL}$ of a mixture DMF-water $(1: 2, \mathrm{v} / \mathrm{v})$.

All sample solutions were gravimetrically prepared using an analytical balance (Shimadzu, Tokyo, Japan), model AUW 220D, with resolution of $0.01 \mathrm{mg}$.

\section{TGA}

The thermogravimetric analysis was performed using a TGA/DSC 1 Star System thermogravimetric analyzer
(Mettler Toledo). The temperature calibration of the equipment was carried out using In, $\mathrm{Zn}, \mathrm{Al}, \mathrm{Au}$ and $\mathrm{Pd}$ reference materials. The analysis consisted of heating 10-20 mg samples, hermetically sealed in an $70 \mu \mathrm{L}$ aluminum pan, in the temperature range between 30 and $400{ }^{\circ} \mathrm{C}$ at a rate of $2.0^{\circ} \mathrm{C} \mathrm{min}^{-1}$, under dynamic nitrogen gas-flow $\left(50 \mathrm{~mL} \mathrm{~min}^{-1}\right)$.

\section{ATR-FTIR}

For ATR-FTIR (attenuated total reflectance infrared spectroscopy) analysis, a GX Spectrum spectrometer (Perkin-Elmer, Waltham, MA, USA) with diffuse reflectance accessory was used. Spectra were recorded by 16 scans in

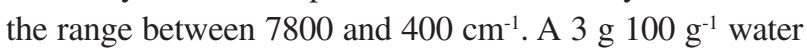
stock solution was prepared in solvent (isopropanol for captopril, methanol for both diclofenacs and acetone for

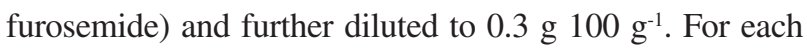
API, $500 \mathrm{mg}$ samples were added to six tubes, which received different volumes of the $0.3 \%$ water solution $(0,0.2,0.5,1.2$, 2.5 and $5.0 \mathrm{~mL}$ ), and then the appropriate solvent volume was added to reach $5 \mathrm{~mL}$ (standard addition method). The water concentrations in the tubes that came from the water stock solution were $0,0.012,0.030,0.072,0.150$ and

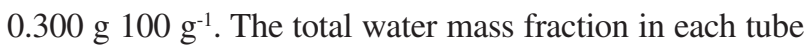
corresponded to the water from API (to be determined), a known water amount from the stock solution, and a known water amount from the solvent, which was determined by Karl Fischer coulometric titration by direct addition in case of isopropanol and methanol. Software Matlab version 6.5 and PLS Toolbox version 4.21, from Eigenvector Technologies, were used to construct multivariate analysis statistical models to determine the water content in the prepared solutions, which were then subtracted by the water content in the solvents to estimate the water amount in APIs.

\section{Samples, reagents and chemicals}

The studies were carried out using the INMETRO first batches of the new CRMs of captopril, metronidazole and sodium diclofenac, as well as the candidate CRMs of potassium diclofenac and furosemide. For the Karl Fischer coulometric titration, a Coulomat AG solution (Riedel-de Haen, Seelze, Germany) was used.

For chromatographic and FTIR analysis, the reagents were methanol and acetone GC grade (Tedia, Rio de Janeiro, Brazil), isopropanol and ethyl acetate HPLC grade (Tedia), $N, N$-dimethylformamide anhydrous $99.8 \%$ (Sigma Aldrich, St. Louis, USA) and water type I (Millipore, Bedford, USA). Before use, DMF and water were purged with nitrogen for $3 \mathrm{~h} \cdot{ }^{37}$ 


\section{Results and Discussion}

Karl Fischer (KF) coulometric titration and loss on drying (LOD) test

Considering the small amount of water in the samples, the coulometric KF titration was considered more appropriate than the volumetric titration. Additionally, since captopril could react with the KF reagent due to the presence of thiol groups, the oven method was preferred over the direct addition method. Figure 1 shows a scatter plot of Karl Fischer vs. loss on drying results for the five studied APIs. It can be seen that captopril, potassium diclofenac and metronidazole deviated from the 45-degree dashed line that corresponds to the agreement between both methods, while furosemide and sodium diclofenac were closer to it. However, the $t$-test of the results shown in Table 2 indicated that the results of both methods could be considered equivalent only for sodium diclofenac. For furosemide, even if the average results of LOD and KF seemed quite similar, the differences in the standard deviations (and variances) led to non-equivalent results in the $t$-test.

As can be seen in Table 2, the ratios between the $\mathrm{LOD}$ and $\mathrm{KF}$ results (LOD/KF ratios) were in the range between 0.85 (furosemide) and 12.0 (metronidazole). The

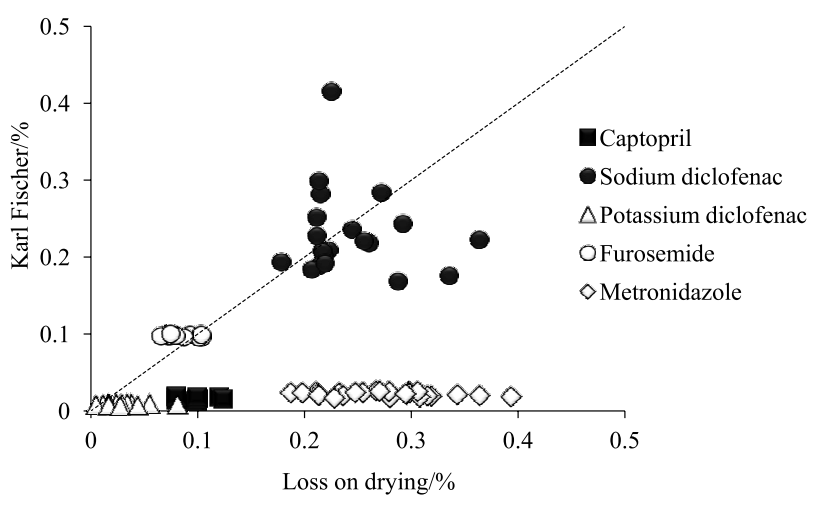

Figure 1. Scatter-plot of Karl Fischer coulometric titration vs. loss on drying results for the five APIs. differences between both method results (LOD - KF) are also shown in this table. Dalton and Hancock ${ }^{6}$ previously reported larger LOD results at $105^{\circ} \mathrm{C}$ compared to $\mathrm{KF}$ results for pharmaceutical excipients, especially in case of low water contents, and presented LOD/KF ratios up to 1.5 (e.g., LOD/KF ratio = 2.56/1.69). Hinz $^{29}$ also observed quite significantly differences in the results obtained using five techniques to determine volatiles in six substances.

The easiest explanation for the observed differences between the loss on drying and Karl Fischer results is that the KF is insensitive to residual solvents. ${ }^{45}$ Therefore, APIs were further analyzed by gas chromatography, as described below, in order to verify if the differences observed between the LOD and KF results could be explained by the presence of residual solvents.

Static headspace gas-chromatography with flame ionization and mass spectrometer detectors (sHS-GC-FID and sHS-GC-MS)

The sHS-GC-FID method was based on the general method proposed by the United States Pharmacopeia 2011 (USP 34$)^{27}$ for determination of residual solvents in pharmaceuticals (USP general method 467). Since only captopril could be dissolved in water (max. $400 \mathrm{mg}$ in $6 \mathrm{~mL}$ ), different proportions of DMF-water were evaluated for API dissolution. The use of at least 2 parts of DMF for each 4 parts of water (DMF-water 2:4, v/v) was the minimum DMF proportion necessary to dissolve $50 \mathrm{mg}$ of all APIs, being furosemide the most problematic. In order to test larger API masses (500 mg API in $6 \mathrm{~mL}$ solution in the headspace vial), the use of DMF-water 5:1 (v/v) as diluent was necessary.

The sHS-GC-FID analysis indicated the presence of a peak with retention times $\left(t_{R}\right)$ of 7.1 min for captopril and another peak with $t_{R}=3.4$ min for furosemide (Figure 2). For the other APIs, only trace amounts of residual solvents with $t_{R}$ between 3.0 and 10.5 min were observed (notice the different scales of $y$-axis in Figures $2 b, 2 c$ and $2 d$ compared to Figures $2 \mathrm{a}$ and $2 \mathrm{e}$ ). Based on the chromatogram of a

Table 2. Summary of results of loss on drying, Karl Fischer coulometric titration (oven method), and sHS-GC-FID for the five APIs

\begin{tabular}{|c|c|c|c|c|c|c|c|c|c|c|c|}
\hline \multirow{2}{*}{ API } & \multicolumn{3}{|c|}{ Loss on drying (LOD) } & \multicolumn{3}{|c|}{ Karl Fischer (KF) } & \multirow{2}{*}{$\begin{array}{c}\text { Ratio } \\
\text { LOD/KF }\end{array}$} & \multirow{2}{*}{ LOD-KF } & \multicolumn{3}{|c|}{ sHS-GC-FID } \\
\hline & $\overline{\mathrm{W}}$ & SD & $\mathrm{n}$ & $\overline{\mathrm{W}}$ & SD & $\mathrm{n}$ & & & $\overline{\mathrm{W}}$ & $\mathrm{SD}$ & $\mathrm{n}$ \\
\hline Captopril & 0.09774 & 0.01546 & 10 & 0.01837 & 0.00306 & 21 & 5.3 & 0.07937 & 0.03809 & 0.00150 & 3 \\
\hline Metronidazole & 0.27411 & 0.05254 & 25 & 0.02292 & 0.00254 & 30 & 12.0 & 0.25119 & 0.00094 & 0.00045 & 3 \\
\hline Sodium diclofenac & 0.25676 & 0.04981 & 32 & 0.23152 & 0.05646 & 20 & 1.1 & 0.02524 & 0.00868 & 0.00019 & 3 \\
\hline Potassium diclofenac & 0.03182 & 0.02102 & 12 & 0.00857 & 0.00107 & 20 & 3.7 & 0.02325 & 0.00154 & 0.00039 & 3 \\
\hline Furosemide & 0.08370 & 0.01354 & 12 & 0.09877 & 0.00238 & 20 & 0.85 & -0.01507 & 0.02261 & 0.00132 & 3 \\
\hline
\end{tabular}

$\overline{\mathrm{W}}$ : mean mass fraction; SD: standard deviation expressed in $\mathrm{g} 100 \mathrm{~g}^{-1} ; \mathrm{n}$ : number of replicates. 

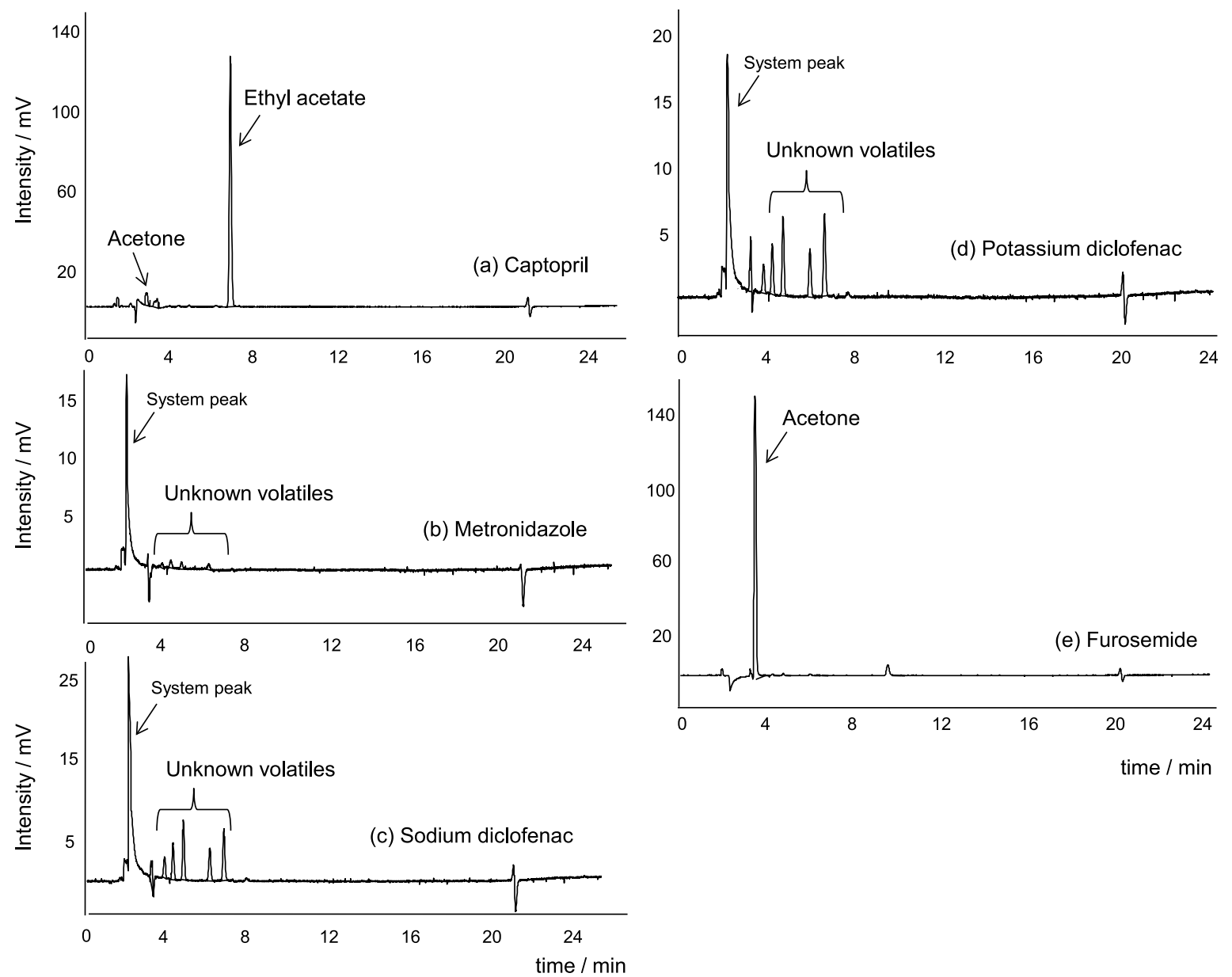

Figure 2. sHS-GC-FID chromatograms for the five APIs. Experimental conditions: see Experimental section.

standard solvent mixture for sHS-GC-FID (Figure 3), there was an indicative that the captopril and furosemide peaks were ethyl acetate $\left(t_{R}=7.1 \mathrm{~min}\right)$, acetone $\left(t_{R}=3.4 \mathrm{~min}\right)$ or isopropanol ( $\left.\mathrm{t}_{\mathrm{R}}=3.7 \mathrm{~min}\right)$.

The sHS-GC-MS analysis confirmed the presence of ethyl acetate (fragment ion: $43.0 \mathrm{amu}, \mathrm{t}_{\mathrm{R}}=7.0 \mathrm{~min}$ ) in captopril (and also some traces in sodium diclofenac), as well as the presence of acetone (fragment ions: 58.1 and $43.1 \mathrm{amu}, \mathrm{t}_{\mathrm{R}}=3.4 \mathrm{~min}$ ) and isopropanol (fragment ion: $45.1 \mathrm{amu}, \mathrm{t}_{\mathrm{R}}=3.7 \mathrm{~min}$ ) in furosemide. Acetone traces were also detected in the other APIs. No other solvent could be identified and the signals eluted after the DMF peak ( $t_{R}$ around $26 \mathrm{~min}$ ) were mainly attributed to column bleeding.

For each of the three solvents (ethyl acetate, isopropanol and acetone), sixteen vials were individually prepared containing increasing solvent masses between 0.003 and $12 \mathrm{mg}$ and $6 \mathrm{~mL}$ DMF-water $(5: 1, \mathrm{v} / \mathrm{v})$, and then analyzed by sHS-GC-FID. The limits of quantitation $(\mathrm{S} / \mathrm{N}=10 \text {, ratio of signal to noise })^{46}$ were estimated to be $3.2 \mu \mathrm{g}$ per vial for ethyl acetate, $4.4 \mu \mathrm{g}$ per vial for isopropanol and $0.42 \mu \mathrm{g}$ per vial for acetone,

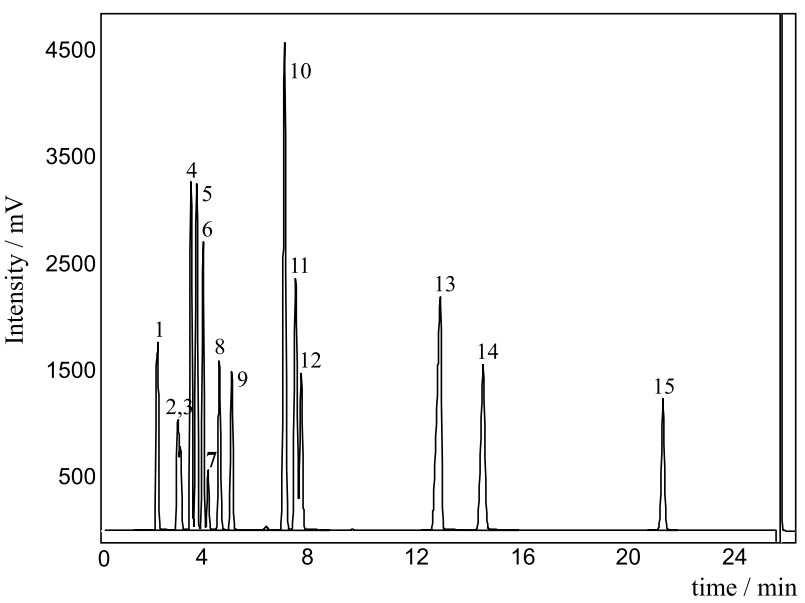

Figure 3. sHS-GC-FID chromatograms for a standard misture of solvents: methanol (1) ( $\left.\mathrm{t}_{\mathrm{R}} 2.3 \mathrm{~min}, 1.67 \mu \mathrm{g} \mathrm{g}^{-1}\right)$, ethanol (2) $\left(\mathrm{t}_{\mathrm{R}} 3.1 \mathrm{~min}, 0.56 \mu \mathrm{g} \mathrm{g}^{-1}\right)$, diethyl ether (co-eluted with ethanol) (3) $\left(\mathrm{t}_{\mathrm{R}} 3.2 \mathrm{~min}, 0.28 \mu \mathrm{g} \mathrm{g}^{-1}\right)$, acetone (4) $\left(\mathrm{t}_{\mathrm{R}} 3.5 \mathrm{~min}, 0.56 \mu \mathrm{g} \mathrm{g}^{-1}\right)$, isopropanol (5) $\left(\mathrm{t}_{\mathrm{R}} 3.8 \mathrm{~min}\right.$, $\left.1.11 \mu \mathrm{g} \mathrm{g}^{-1}\right)$, acetonitrile (6) $\left(\mathrm{t}_{\mathrm{R}} 4.0 \mathrm{~min}, 1.11 \mu \mathrm{g} \mathrm{g}^{-1}\right)$, dichloromethane (7) $\left(\mathrm{t}_{\mathrm{R}} 4.2 \mathrm{~min}, 1.67 \mu \mathrm{g} \mathrm{g}^{-1}\right)$, methyl tert-butyl ether (8) $\left(\mathrm{t}_{\mathrm{R}} 4.6 \mathrm{~min}, 0.56 \mu \mathrm{g} \mathrm{g}^{-1}\right)$, $n$-hexane (9) $\left(\mathrm{t}_{\mathrm{R}} 5.1 \mathrm{~min}, 1.11 \mu \mathrm{g} \mathrm{g}^{-1}\right)$, ethyl acetate (10) $\left(\mathrm{t}_{\mathrm{R}} 7.10 \mathrm{~min}\right.$, $\left.0.56 \mu \mathrm{g} \mathrm{g}^{-1}\right)$, THF (11) $\left(\mathrm{t}_{\mathrm{R}} 7.5 \mathrm{~min}, 0.28 \mu \mathrm{g} \mathrm{g}^{-1}\right)$, chloroform (12) $\left(\mathrm{t}_{\mathrm{R}} 7.7 \mathrm{~min}\right.$, $\left.0.14 \mu \mathrm{g} \mathrm{g}^{-1}\right), n$-butyl alcohol (13) ( $\left.\mathrm{t}_{\mathrm{R}} 13.0 \mathrm{~min}, 1.67 \mu \mathrm{g} \mathrm{g}^{-1}\right), 1,4$-dioxane (14) $\left(\mathrm{t}_{\mathrm{R}} 14.6 \mathrm{~min}, 1.67 \mu \mathrm{g} \mathrm{g}^{-1}\right)$, and toluene (15) $\left(\mathrm{t}_{\mathrm{R}} 21.5 \mathrm{~min}, 0.83 \mu \mathrm{g} \mathrm{g}^{-1}\right)$. Experimental conditions: see Experimental section. 
which were similar to those reported in the literature (0.01-20 $\mu \mathrm{g}$ per vial) ${ }^{37}$ Considering the API mass of 0.5 $\mathrm{g}$ per vial to be later analyzed, the limits of quantification could be expressed as $6.4 \mathrm{ppm}$ for ethyl acetate, $8.8 \mathrm{ppm}$ for isopropanol and $0.83 \mathrm{ppm}$ for acetone.

Calibration curves were then constructed for each of the three solvents, using eight data points in the mass range between the limit of quantitation and $0.5 \mathrm{mg}$, which was considered the most appropriate working range (Figure 4). After the sHS-GC-FID analysis of the five APIs (0.5 g per vial dissolved in $6 \mathrm{~mL}$ DMF-water, 5:1), the curves were used to determine the residual solvents in APIs (external standard calibration). The results can be seen in the last columns of Table 2. For small unknown peaks, the isopropanol calibration curve was considered.

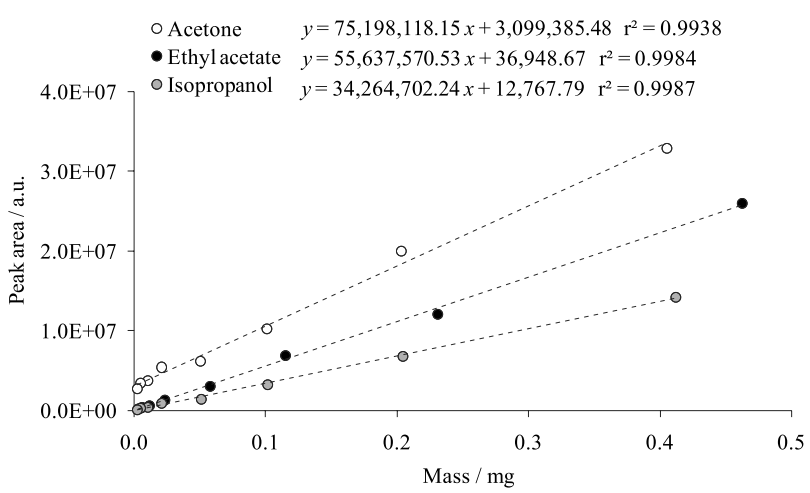

Figure 4. sHS-GC-FID calibration curves for ethyl acetate, isopropanol and acetone. Experimental conditions: see Experimental section.

\section{Differences between LOD and KF results}

Contrary to the expectations, for captopril, both diclofenacs and metronidazole, the differences between LOD and KF results (LOD - KF) shown in Table 2 could be only partially explained by the presence of residual solvents. One of the reasons for that may be the previously reported difficulty to completely remove polar residual solvents from sample solutions for sHS-GC analysis. ${ }^{33,36}$ Chen et al. ${ }^{38}$ for instance, studied the recoveries of 44 residual solvents in pharmaceuticals and reported values as low as $57 \%$ for acetone at 2-90 ppm levels. Another possible reason why the volatile mass fraction did not match the difference LOD - KF may be related to solvent-solute effects, ${ }^{47}$ which means interactions between APIs and residual solvents in solution.

For furosemide, the LOD/KF ratio of 0.85 may be possibly explained by the presence of acetone as the main residual solvent, as confirmed by sHS-GC-FID and sHS-GC-MS. Acetones (and aldehydes) react with the KF reagent to form acetals and ketals through dehydration, ${ }^{29}$ which is the probable reason why furosemide showed a slightly larger amount of water (KF) compared to the total amount of volatiles determined by LOD.

\section{Thermogravimetric analysis}

The results for the thermogravimetric analysis (TGA) of the five APIs are shown in Figure 5. For each API, the upper curve corresponds to the API mass $v s$. the temperature of the experiment ( 30 to $400{ }^{\circ} \mathrm{C}$, at $2{ }^{\circ} \mathrm{C} \mathrm{min}{ }^{-1}$ rate), while the lower curve corresponds to its first derivative, which makes easier the identification of the temperatures at which the material degradation occurs. The dark arrows in Figure 5 indicate the decomposition of the analytes. Only for furosemide, a mass loss (around 2.47\%) was observed before the main API decomposition signal, at around 210 ${ }^{\circ} \mathrm{C}$, in the region indicated by a white arrow in Figure 5e. Previous studies indicated that this mass loss corresponds to one of the three furosemide degradation steps. ${ }^{48}$ For all APIs, no water loss was observed in the usual range (room temperature to $100{ }^{\circ} \mathrm{C}$ ), ${ }^{32}$ which can be explained by the low TGA sensitivity.

\section{Near infrared spectroscopy}

Although it was previously reported in the literature the strong absorption bands for water in the NIR spectral region (7800 to $400 \mathrm{~cm}^{-1}$ ), for instance at $5209 \mathrm{~cm}^{-1}$, 43 the determination of water by ATR-FTIR analysis of solutions containing $0.5 \mathrm{~g}$ of API and increasing water amounts (standard addition method) in a specific solvent, combined with multivariate analysis statistical methods for results evaluation, had several drawbacks: (i) due to the low sensitivity of NIR spectroscopy, the water bands for such low water content solutions could not be easily identified in the NIR spectral regions. As an example, the spectra of six captopril solutions added of 0 to $3.75 \mu \mathrm{g} \mathrm{g}^{-1}$ water were practically superimposed (Figure 6); (ii) metronidazole could not be analyzed since none of the tested solvents was able to dissolve it in the proportion used $(0.5 \mathrm{~g}$ in $5 \mathrm{~mL})$; (iii) the water mass fractions estimated by chemometric methods corresponded to the sum of the water contents from API and solvent. Therefore, it was necessary to determine the original water content in the solvents by KF coulometric titration, for further subtraction. In the case of furosemide, the only solvent able to dissolve it was acetone, which reacts with the KF reagent and could not be analyzed by this technique.

Even if multivariate analysis statistical models could be constructed from the NIR spectra of captopril (Figure 6) and both diclofenacs, with squared correlation coefficients $r^{2}$ of at least 0.95 , the estimated mass fractions 

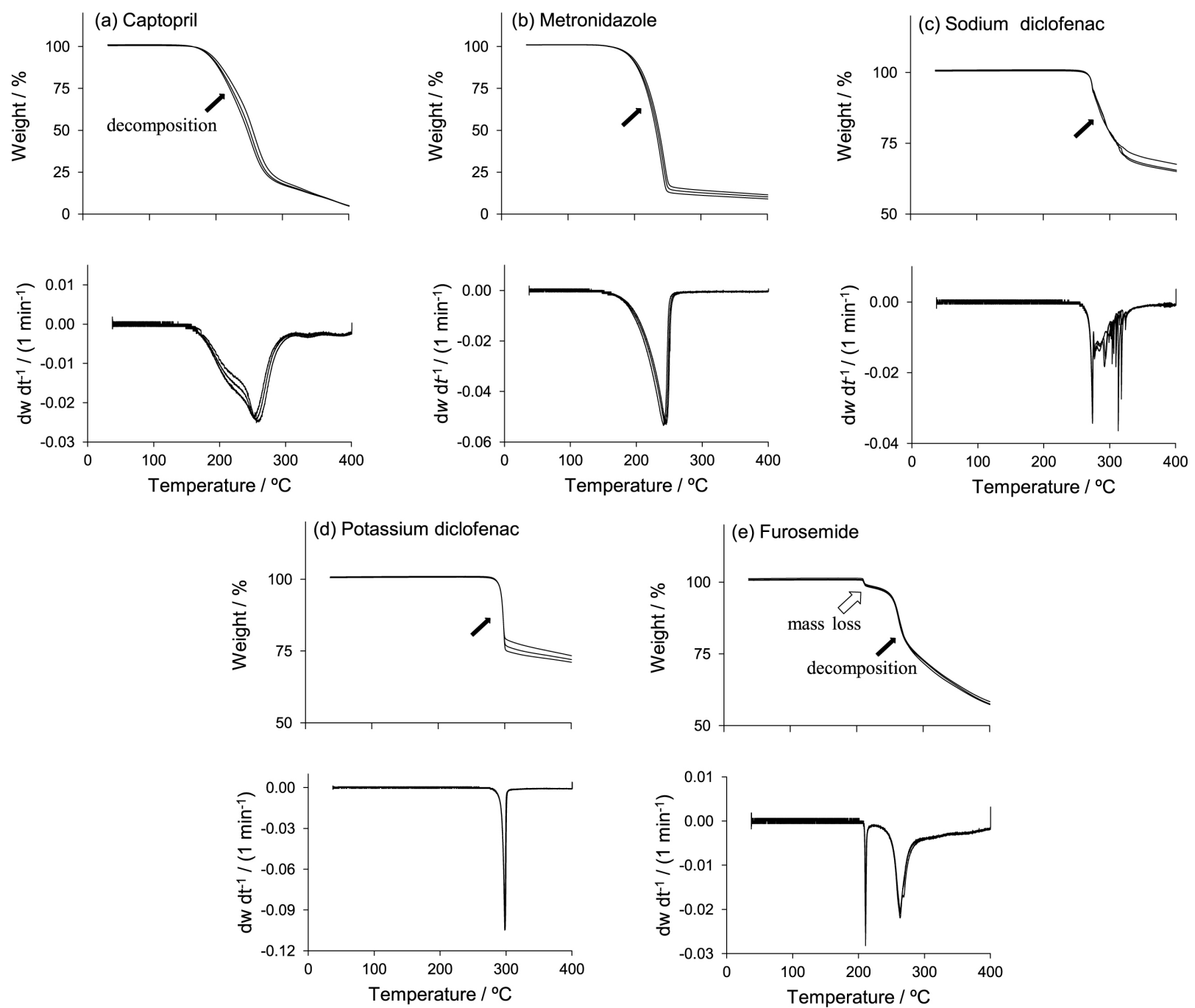

Figure 5. TGA results for APIs of captopril (a), metronidazole (b), sodium diclofenac (c), potassium diclofenac (d) and furosemide (e). For each API, the curves of mass $v s$. temperature (upper curve) and the corresponding $1^{\text {st }}$ derivative (lower curve) are shown. The dark arrows show the API decomposition, while the white arrow indicates a mass loss of $2.47 \%$ at $210^{\circ} \mathrm{C}$ for furosemide.

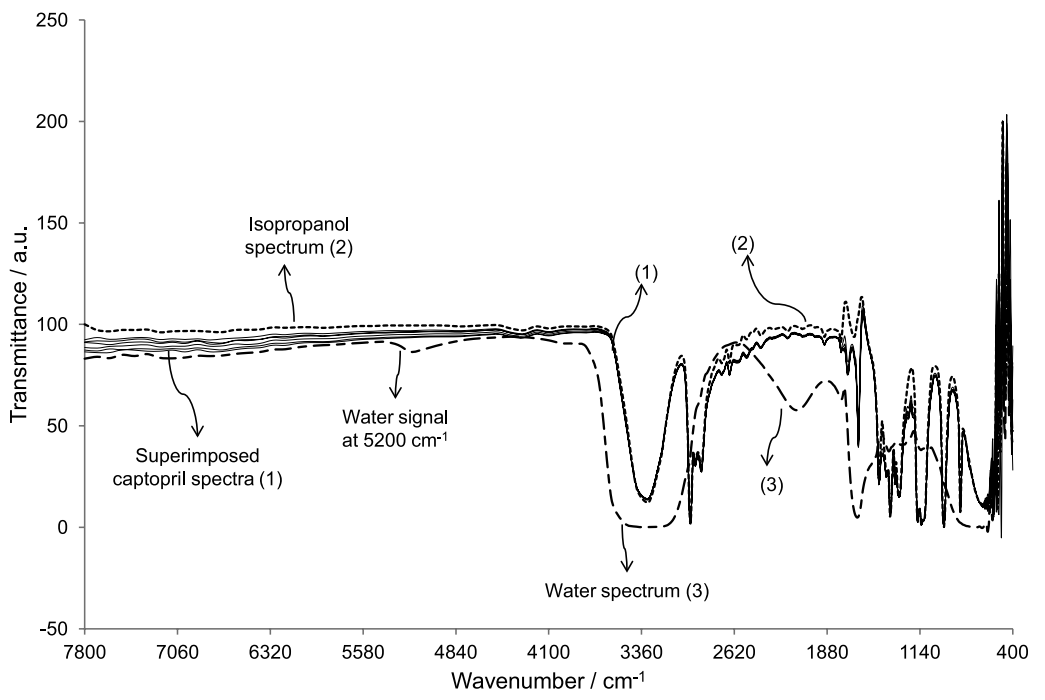

Figure 6. NIR spectra for six captopril solutions in isopropanol containing $0.00,0.13,0.36,0.88$ and $3.75 \mu \mathrm{g} \mathrm{g}^{-1}$ water (superimposed spectra) (1), for isopropanol (2) and water (3), used to construct multivariate calibration models. 


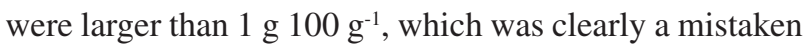
result. However, the technique may still be considered for APIs with larger water contents.

\section{Conclusions}

The determination of volatiles in active pharmaceutical ingredients (API) is essential due to their possible toxicity and influence on the physicochemical and microbiological properties of raw materials and finished pharmaceutical products. Volatiles also have to be quantified in case of determination of API purity by mass balance, as performed in the development of pharmaceutical CRMs.

Five different analytical techniques were applied to three new CRMs of captopril, metronidazole and sodium diclofenac, and to the two candidate CRMs of potassium diclofenac and furosemide. For captopril, both diclofenacs and metronidazole, the differences between the loss on drying (LOD) (quantitation of water and residual solvents) and Karl Fischer (KF) coulometric titration (water quantitation) could be partially explained by the presence of residual solvents determined by sHS-GC-FID, and were mainly attributed to chromatographic recoveries smaller than $100 \%$ or possible solvent-solute interactions. For furosemide, the increased KF results $(\mathrm{LOD} / \mathrm{KF}$ ratio $=0.85)$ were attributed to the presence of acetone, which reacts with the KF reagent. Therefore, from these three evaluated techniques, the oldest loss on drying technique was considered the most appropriate to determine the mass fraction of the volatiles to be used in the mass balance calculation of API mass fraction in pharmaceutical CRMs.

The two other analytical methods evaluated, TGA and ATR-NIR-chemometrics, were not sufficiently sensitive to determine water or volatiles in the concentration ranges present in APIs. However, they may find application for APIs containing larger volatile mass fractions.

\section{Acknowledgements}

The authors thank Nova Analítica Importação e Exportação Ltda for lending the headspace GC-FID system (Thermo Scientific) used in the experiments.

\section{References}

1. Caramasu, C.; Madichie, C.; Williams, R.; TrAC, Trends Anal. Chem. 2006, 25, 768.

2. D'Autry, W.; Zheng, C.; Wolfs, K.; Yarramraju, S.; J. Sep. Sci. 2011, 34, 1299.
3. Witschi, C.; Doelker, E.; Eur. J. Pharm. Biopharm. 1997, 43, 215.

4. Cha, J.; Ranweiler, J. S.; Lane, P. A. In Handbook of Modern Pharmaceutical Analysis; Ahuja, S.; Scypinski, S., eds.; Academic Press: London, 2001.

5. Cao, W.; Mao, C.; Chen, W.; Lin, H.; Krishnan, S.; Cauchon, N.; J. Pharm. Sci. 2006, 95, 2077.

6. Dalton, C. R.; Hancock, B. C.; Int. J. Pharm. 1997, 156, 143.

7. Jain, R.; Railkar, A. S.; Malick, A. W.; Rhodes, C. T.; Shah, N. H.; Eur. J. Pharm. Biopharm. 1998, 46, 177.

8. Fliszar, K.; Wiggins, J. M.; Pignoli, C. M.; Martin, G. P.; Li, Z.; J. Chromatogr., A 2004, 1027, 83.

9. Isengard, H.; Food Chem. 2008, 106, 1393.

10. Ishikawa, K.; Hanari, N.; Shimizu, Y.; Ihara, T.; Nomura, A.; Numata, M.; Yarita, T.; Kato, K.; Koichi, C.; Accredit. Qual. Assur. 2011, 16, 311.

11. Yip, Y.; Wong, S.; Choi, S.; TrAC, Trends Anal. Chem. 2011, 30, 628 .

12. Gorog, S.; J. Pharm. Biomed. Anal. 2005, 36, 931.

13. ISO Guide 34: General Requirements for the Competence of Reference Material Producers, ISO: Geneva, 2009.

14. ISO Guide 35: Reference Materials: General and Statistical Principles for Certification, ISO: Geneva, 2006.

15. Joint Committee for Guides in Metrology (JCGM); International Vocabulary of Metrology: Basic and General Concepts and Associated Terms (VIM), $3^{\text {rd }}$ ed.; BIPM: Sèvres, France, 2008.

16. Duewer, D. L.; Parris, R. M.; White, E. V.; May,W.E.; Elbaum, H.; An Approach to the Metrologically Sound Traceable Assessment of the Chemical Purity of Organic Reference Materials; National Institute of Standards and Technology (NIST): Gaithersburg, USA, 2004.

17. ABNT NBR ISO/IEC 17025: Requisitos Gerais para Competência de Laboratórios de Ensaio e Calibração, ABNT: Rio de Janeiro, Brasil, 2005.

18. United States Pharmacopeial Convention, http://www.usp.org accessed in March 2012.

19. National Metrology Institute of Japan (NMIJ), List of NMIJ Certified Reference Materials, http://www.nmij.jp/english/ service/C/crm/ accessed in March 2012.

20. Liu, J.; Yang, G.; Acta Metrol. Sin. 2010, 31, 135.

21. Nogueira, R.; Rego, E. C. P.; Sousa, M. V. B.; Wollinger, W.; Silva, T. E.; Moreira, G. F.; Barin, J. S.; Laporta, L. V.; Mesko, M. F.; Bittencourt, C. F.; Rodrigues, J. M.; Cunha, V. S.; Braz. J. Pharm. Sci. 2011, 47, 339.

22. Nogueira, R.; Wollinger, W.; Silva, T. E.; Oliveira, L. M.; Rego, E. C. P.; Moreira, G. F.; Barin, J. S.; Laporta, L. V.; Mesko, M. F.; Bittencourt, C. F.; Rodrigues, J. M.; Cunha, V. S.; Braz. J. Pharm. Sci. 2011, 47, 351.

23. Nogueira, R.; Rocha, W. F. C.; Silva, T.E.; Rego, E. C. P.; Moreira, G. F.; Wollinger, W.; Rodrigues, J. M.; J. Braz. Chem. Soc. 2012, 23, 435. 
24. De Caro, C. A.; Aichert, A.; Walter, C. M.; Food Control 2001 , $12,431$.

25. Emery, E.; Oliver, J.; Pugsley, T.; Sharma, J.; Zhou, J.; Powder Technol. 2009, 189, 409.

26. International Conference on Harmonisation of Technical Requirements for Registration of Pharmaceuticals for Human Use (ICH); Guideline for Residual Solvents Q3C(R5); ICH: London, 2011.

27. The United States Pharmacopeia, USP 34-NF 29, The United States Pharmacopeial Convention: Rockville, 2011.

28. Grünke, S.; Food Control 2001, 12, 419.

29. Hinz, D. C.; J. Pharm. Biomed. Anal. 2007, 43, 779.

30. Felgner, A.; Schlink, R.; Kirschenbühler, P.; Faas, B.; Isengard, H.; Food Chem. 2008, 106, 1379.

31. Sherman, F.; Kuselman, I.; Int. J. Pharm. 1999, 190, 193.

32. Towns, J. K.; J. Chromatogr., A 1995, 705, 115.

33. B'Hymer, C.; Pharm. Res. 2003, 20, 337.

34. Hong, L.; Althofer, H. R.; Pharm. Acta Helv. 1997, 72, 95.

35. Mulligan, K. L.; Brueggemeyer, T. W.; Crockett, D. F.; Schepman, J. B.; J. Chromatogr., B: Anal. Technol. Biomed. Life Sci. 1996, 686, 85.

36. Pandey, S.; Pandey, P.; Kumar, R.; Singh, N. P.; Braz. J. Pharm. Sci. 2011, 47, 379.

37. Sitaramaraju, Y.; van Hul, A.; Wolfs, K.; van Schepdael, A.; Hoogmartens, J.; Adams, E.; J. Pharm. Biom. Anal. 2008, 47, 834.
38. Chen, C.; Liu, S.; Mueller, B.; Yan, Z.; J. Chromatogr., A 2010, 1217, 6413.

39. Otero, R.; Carrera, G.; Dulsat, J. F.; Fábregas, J. L.; Claramunt, J.; J. Chromatogr., A 2004, 1057, 193.

40. Cervera, M. I.; Beltran, J.; Lopez, F. J.; Hernandez, F.; Anal. Chim. Acta 2011, 704, 87.

41. Roggo,Y.; Chalus, P.; Maurer,L.; Lema-Martinez, C.; Edmond,A.; Jent, N.; J. Pharm. Biomed. Anal. 2007, 44, 683.

42. Hausman, D.; Cambron, R. T.; Sakr, A.; Int. J. Pharm. 2005, $229,19$.

43. Zhou, X.; Hines, P.; Borer, M. W.; J. Pharm. Biom. Anal. 1998, 17, 219.

44. Farmacopeia Brasileira, 4a. ed.; Atheneu: São Paulo, Brasil, 2002.

45. Smith, R. J.; Webb, M. L.; Analysis of Drug Impurities; Blackwell Publishing: Oxford, 2007.

46. International Conference on Harmonisation of Technical Requirements for Registration of Pharmaceuticals for Human Use (ICH); Validation of Analytical Procedures: Text and Methodology Q2(R1); ICH: London, 2005.

47. Kumar, N.; Gow, J. G.; J. Chromatogr., A 1994, 667, 235.

48. Valladao, D. M. S.; Oliveira, L. C. S.; Netto, J. Z.; Ionashiro, M.; J. Therm. Anal. 1996, 46, 1291.

Submitted: December 7, 2011 Published online: August 15, 2012 